\title{
Abortamento legal: comparação do grau de conhecimento de médicos de um hospital especializado em atendimento à mulher e de um hospital geral
}

\section{Legal abortion: comparison of the extent of the knowledge of doctors at a women's care hospital and a general hospital}

\author{
Rubens Rossati França Junior ${ }^{1}$, Marcela Valério Braga², Carmen Silvia \\ Molleis Galego Miziara ${ }^{3}$, Ivan Dieb Miziara ${ }^{4}$
}

\begin{abstract}
França Junior RR, Braga MV, Miziara CSMG, Miziara ID. Abortamento legal: comparação do grau de conhecimento de médicos de um hospital especializado em atendimento à mulher e de um hospital geral. Saúde, Ética \& Justiça. 2015;20(2):57-65.

RESUMO: No Brasil, o abortamento é considerado crime, exceto em algumas condições. Sendo assim, é fundamental que os profissionais de saúde conheçam tais situações para que possam conduzir adequadamente os casos. O objetivo desse estudo foi comparar o grau de conhecimento de médicos de um hospital especializado no atendimento de mulheres com médicos de um hospital geral, na cidade de Santo André, sobre abortamento permitido por lei no Brasil. Para atingir tal finalidade, foi aplicado um questionário estruturado com questões relativas ao abortamento aprovado pelo Comitê de Ética Médica. O resultado do presente estudo mostrou que não houve diferença significativa entre os dois grupos quanto às questões sociais e legais envolvidas no abortamento, exceto em três situações em que o grupo de médicos do hospital especializado mostrou maior conhecimento quanto às questões envolvendo a doença mental da gestante, o controle de natalidade e a utilização da ocitocina como fármaco indutor de abortamento.
\end{abstract}

DESCRITORES: Aborto; Aborto legal; Aborto terapêutico; Legislação; Médicos hospitalares/legislação \& jurisprudência.

1. Estudante de medicina da Faculdade de medicina do ABC

2. Residente de Medicina Legal da Universidade de São Paulo.

3. Professora Auxiliar da Disciplina de Medicina Legal, Deontologia Médica, Bioética e Perícias Médicas da Faculdade de Medicina do ABC.

4. Professor titular da Disciplina de Medicina Legal, Deontologia Médica, Bioética e Perícias Médicas da Faculdade de Medicina do ABC e Professor Associado do Departamento de Medicina Legal, Ética Médica, Medicina Social e do Trabalho da Faculdade de Medicina da Universidade de São Paulo.

Endereço para correspondência: Rubens Rossati França Junior. Faculdade de Medicina do ABC. Avenida Príncipe de Gales, 821 - Vila Príncipe de Gales, Santo André - SP. CEP: 09060-650. E-mail rfmed@hotmail.com 


\section{INTRODUÇÃO}

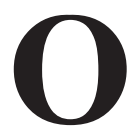
conceito de abortamento no entendimento médico não é o mesmo do jurídico-penal. No primeiro, o abortamento é a interrupção do processo gestacional até a $20^{\mathrm{a}}$ ou $22^{\mathrm{a}}$ semana de gravidez, desde que o produto da concepção (feto) pese menos de 500 gramas $^{1}$, No aspecto jurídico-penal o abortamento é a conduta de interrupção da gestação a qualquer tempo, antes de seu termo final, dolosamente causando a morte fetal ${ }^{2}$. Portanto, no que tange ao tema abortamento criminal, a idade do feto não é de interesse médico-legal ${ }^{3}$, mas, sim, a interrupção voluntária da gestação pela gestante ou por terceiros.

A prática de abortamento é prevista como crime contra a vida, de acordo com o Código Penal Brasileiro, exceto em duas condições: quando não existe outro meio de salvar a vida da gestante (aborto necessário); na gravidez resultante de estupro ou de outra forma de violência sexual (aborto sentimental), mediante a autorização da gestante ou, quando ela for incapaz, de seu representante legal (art. 128, incisos I e II, respectivamente, do Código Penal ${ }^{2}$. Existe uma outra condição, não constante no Código Penal, que se refere aos casos de fetos anencéfalos, sendo esta condição instituída pela Arguição de Descumprimento de Preceito Fundamental $\mathrm{n}^{\circ}$. 54, votada e aprovada em 12 de abril de 2012 pelo Supremo Tribunal Federal ${ }^{4}$ e normatizada pelo Conselho Federal de Medicina, através da Resolução CFM nº. 1.989/2012 que dispõe sobre os critérios diagnósticos de anencefalia para a antecipação terapêutica do parto 5 .

Nos casos de gestação decorrente de estupro não existe o dever legal de a vítima noticiar o fato à autoridade policial, embora deva ser orientada para fazê-lo, para a realização da interrupção da gestação por médico ${ }^{6}$. A interrupção da gestação somente será efetuada com o consentimento da vítima e, para efeito legal, a capacidade de consentimento está determinada pelo Código Civil ${ }^{7}$. Mulheres a partir dos 18 anos de idade são consideradas capazes de consentir sozinhas para a realização do abortamento, aquelas entre 16 e 18 anos devem ser assistidas pelos pais ou pelo representante legal que se manifestam com ela. As crianças ou adolescentes com idade inferior a 16 anos são representadas pelos pais ou por seus representantes legais, que se manifestam por ela ${ }^{7}$.

Em estudo realizado por Loureiro e Vieira ${ }^{8}$ com médicos da cidade de Ribeirão Preto - SP, foi observado que o nível de conhecimento dos médicos sobre as leis que regem as questões referentes ao abortamento no Brasil foi alto em $22 \%$, médio em $46 \%$ e baixo em $31,5 \%$ dos participantes. No mesmo ano, Faundes et al. ${ }^{9}$ descreveram que as condutas de médicos ginecologistas e obstetras brasileiros associados à Federação Brasileira das
Associações de Ginecologia e Obstetrícia (FEBRASGO) eram pautadas em baixo conhecimento de situação legal relativa a abortamento, apesar de a maioria ter atitudes e condutas favoráveis. Estudo que avaliou o conhecimento de estudantes de Medicina de uma Faculdade da Bahia ${ }^{10}$ mostrou que 59,8\% foram considerados bem informados acerca do tema aborto e que menos da metade $(48,9 \%)$ tinha conhecimento dos aspectos legais do abortamento no Brasil.

No Brasil existem normas técnicas desenvolvidas pelo Ministério da Saúde sobre o tema ${ }^{6,11}$, e legislações específicas, tais como: Lei $\mathrm{n}^{0} 11.340^{12}$, de 7 de agosto de 2006, conhecida como Lei Maria da Penha; Lei ${ }^{\circ}$ 10.778/2003 ${ }^{13}$; Portaria $n^{0} 1.508 / 2005^{14}$; e Resolução $n^{0}$ 1.989/2012 do Conselho Federal de Medicina ${ }^{5}$ (CFM), sendo que esta última versa sobre a anencefalia.

Diante de baixo grau de conhecimento de médicos sobre as bases legais relativas ao abortamento no Brasil, incluindo os casos de gravidez de feto anencéfalo, fazse necessária a realização de estudos que abordem estas questões para que as mulheres e seus familiares possam ser assistidos dentro dos princípios legais e éticos.

\section{OBJETIVO}

O objetivo deste estudo foi comparar o grau de conhecimento de médicos de um hospital especializado no atendimento de mulheres com o de médicos de um hospital geral, na cidade de Santo André, sobre abortamento permitido por lei no Brasil.

\section{MÉTODO}

Foi realizado estudo descritivo transversal através de aplicação de questionário, elaborado pelos investigadores, estruturado abordando o grau de conhecimento de médicos sobre abortamento legal no Brasil. A obtenção da amostra foi aleatória (foram sorteados dez dias do mês durante o período analisado e o questionário foi apresentado aos médicos que estavam de plantão) e composta por dois grupos de médicos. O grupo de estudo foi composto por médicos de um Hospital especializado na saúde da mulher - Hospital da Mulher Maria José dos Santos Stein (GE) e o grupo controle foi de médicos atuantes em um hospital geral, que também atende mulheres, mas estes médicos não são especialistas - Hospital Estadual Mário Covas (GC), ambos localizados na cidade de Sato André, Estado de São Paulo. O período de aplicação do questionário foi de $1^{\circ}$ de agosto a 31 de outubro de 2013. Ambas as Unidades expressaram, por escrito, autorização para que o questionário fosse aplicado.

Este o estudo foi aprovado pelo Comitê de Ética Médica da Faculdade de Medicina do ABC, $\mathrm{n}^{\circ}$. 361.489. Não houve conflito de interesse ou patrocínio.

Os critérios de inclusão foram: ambos os 
França Junior RR et al. Abortamento legal: comparação do grau de conhecimento de médicos de um hospital especializado.

sexos; e idade entre 23 a 55 anos; médicos formados e devidamente registrados no Conselho Regional de Medicina do Estado de São Paulo e pertencentes ao quadro clínico do Hospital da Mulher Maria José dos Santos Stein e Hospital Estadual Mário Covas; assinatura do Termo de Consentimento Livre e Esclarecido. Os critérios de exclusão foram: questionários incompletos ou com rasuras. Os médicos respondiam as perguntas nos horários de repouso. Muitos questionários foram excluídos, pois os médicos não conseguiram completar as respostas devido à demanda de atendimento. Nestes casos, os questionários não foram reaplicados. $\mathrm{O}$ questionário estruturado autoaplicável foi elaborado com a participação de professores da disciplina de Ginecologia e Obstetrícia (GO) da Faculdade de Medicina do ABC e foi composto por três partes. Na primeira parte foram obtidas informações demográficas dos participantes, tais como: idade, tempo de formação, estado civil, religião e paternidade/maternidade. Também foram obtidas, nessa primeira abordagem, informações quanto à(s) disciplina(s) na(s) qual(is) foram dados ensinamentos sobre a questão do abortamento durante a graduação médica (Medicina Legal e Perícia Médica (MLPM), GO ou em ambas). A segunda parte foi composta por sete questões e se destinou à abordagem sobre os conhecimentos gerais sobre o abortamento. As perguntas tinham como possibilidades de respostas apenas de verdadeira (V) ou falsa (F). A última parte, formada por 12 questões, abordou os graus de conhecimento dos participantes quanto à legislação vigente e à prática médica. O preenchimento do questionário foi manual, na presença do examinador, no Hospital da Mulher Maria José dos Santos Stein e no Hospital Estadual Mário Covas.

Os dados foram encaminhados para tratamento estatístico, com a realização de teste qui-quadrado e por meio de frequência absoluta e relativa. O programa utilizado foi o STATA 11.0. O grau de significância considerado foi de $95 \%$.

\section{RESULTADOS}

Foram avaliadas as respostas de 60 médicos, sendo 25 homens e 35 mulheres. $O$ grupo foi subdividido em dois: GE (Hospital da Mulher) com 18 respondentes e GC (Hospital Geral) com 42 participantes. A idade dos sujeitos variou entre 23 e 55 anos, sendo sete entre 23 e 26 anos, 25 entre 27 e 30 anos e 28 acima de 31 anos e abaixo de 55 anos. As principais características sociodemográficas dos participantes estão expostas na Tabela 1. Na graduação, o tema abortamento foi ministrado somente na disciplina de GO para $40 \%$ dos participantes, somente na de MLPM para $11,66 \%$ e em ambas para $48,33 \%$.

Tabela 1. Dados sociodemográficos dos grupos de estudo

\begin{tabular}{|c|c|c|c|c|c|}
\hline \multicolumn{3}{|c|}{ Grupo de estudo } & \multicolumn{3}{|c|}{ Grupo controle } \\
\hline \multicolumn{6}{|c|}{ Sexo } \\
\hline \multicolumn{2}{|r|}{ Feminino } & Masculino & Feminino & \multicolumn{2}{|c|}{ Masculino } \\
\hline \multicolumn{2}{|r|}{12} & 06 & 23 & & \\
\hline \multicolumn{6}{|c|}{ Idade (anos) } \\
\hline $23-26$ & $27-30$ & $31-55$ & $23-26$ & $27-30$ & $31-55$ \\
\hline $\mathrm{n}$ & $\mathrm{n}$ & $\mathrm{n}$ & $\mathrm{n}$ & $\mathrm{n}$ & $\mathrm{n}$ \\
\hline 03 & 09 & 06 & 04 & 16 & 22 \\
\hline \multicolumn{6}{|c|}{ Estado civil } \\
\hline \multicolumn{2}{|r|}{ Solteiro } & Casado & Solteiro & \multicolumn{2}{|c|}{ Casado } \\
\hline \multicolumn{2}{|r|}{13} & 5 & 28 & \multicolumn{2}{|c|}{14} \\
\hline \multicolumn{6}{|c|}{ Filhos } \\
\hline \multicolumn{2}{|r|}{ Sim } & Não & Sim & \multicolumn{2}{|c|}{ Não } \\
\hline \multicolumn{2}{|r|}{02} & 16 & 08 & \multicolumn{2}{|c|}{34} \\
\hline \multicolumn{6}{|c|}{ Tempo de formado (anos) } \\
\hline $1-5$ & $6-10$ & $>10$ & $1-5$ & $6-10$ & $>10$ \\
\hline 22 & 12 & 08 & 10 & 03 & 05 \\
\hline
\end{tabular}

Grupo controle: Hospital Estadual Mário Covas; Grupo de estudo: Hospital da Mulher Maria José dos Santos Stein

A Tabela 2 exibe as respostas dos participantes quanto às consequências do abortamento do ponto de vista médico e social. A maioria dos respondentes, $89 \%$ do GE e 92,86\% do GC, considerou que não é o número da prole o fator determinante de as mulheres recorrerem à interrupção da gestação, mas consideraram que esta 
prática é um problema de saúde pública em decorrências dos ricos a que se expõem as mulheres. De acordo com os participantes do GE o abortamento representa uma maneira de controle de natalidade, contrariamente ao entendimento dos respondentes do GC $(\mathrm{p}<0,05)$. A maioria dos médicos $(55,5 \%$ do GE e $66,67 \%$ do GC) respondeu que a legislação que norteia a questão do abortamento no Brasil está disposta no Código Civil
Brasileiro. Dentre as respostas, 39\% dos médicos do GE e $26,2 \%$ do GC afirmaram que o abortamento no Brasil não representa uma das principais causas de mortalidade de mulheres. Quanto ao fármaco utilizado para a indução do abortamento, houve diferença estatística, sendo que 19 os médicos do GC $(45,23 \%)$ e 02 do GE (11\%) consideraram a oxitocina como o fármaco escolhido $(\mathrm{p}<0,05)$.

Tabela 2. Comparação da incidência de acertos dos grupos em respostas às afirmativas sobre questões gerais sobre o aborto e significância $\chi^{2}(\mathrm{p}<0,05)$

\begin{tabular}{|c|c|c|c|c|c|}
\hline \multirow[t]{2}{*}{ Afirmativas } & \multicolumn{2}{|c|}{$\begin{array}{l}\text { Grupo de estudo } \\
(\%)\end{array}$} & \multicolumn{2}{|c|}{$\begin{array}{l}\text { Grupo controle } \\
(\%) \\
\end{array}$} & \multirow[t]{2}{*}{$\chi^{2}(p)$} \\
\hline & $\mathrm{V}$ & $\mathrm{F}$ & $\mathrm{V}$ & $\mathrm{F}$ & \\
\hline $\begin{array}{l}\text { 1. O grande número de mulheres que recorrem ao abortamento } \\
\text { provocado no Brasil consiste naquelas que excederam o número } \\
\text { desejado de filhos }\end{array}$ & $\begin{array}{c}2 \\
(11)\end{array}$ & $\begin{array}{c}16 \\
(89)\end{array}$ & $\begin{array}{c}3 \\
(7)\end{array}$ & $\begin{array}{c}39 \\
(92,86)\end{array}$ & $\begin{array}{c}0,975<\mathrm{p}< \\
0,50\end{array}$ \\
\hline 2. O abortamento provocado é um problema de saúde pública & $\begin{array}{c}18 \\
(100)\end{array}$ & 0 & $\begin{array}{c}42 \\
(100)\end{array}$ & 0 & * \\
\hline $\begin{array}{l}\text { 3. O abortamento provocado pode trazer riscos a uma futura gesta- } \\
\text { ção }\end{array}$ & $\begin{array}{c}18 \\
(100)\end{array}$ & 0 & $\begin{array}{c}42 \\
(100)\end{array}$ & 0 & * \\
\hline 4. O abortamento contribui para o controle de natalidade no Brasil & $\begin{array}{c}16 \\
(89)\end{array}$ & $\begin{array}{c}2 \\
(11)\end{array}$ & $\begin{array}{c}2 \\
(4,76)\end{array}$ & $\begin{array}{c}40 \\
(95,24)\end{array}$ & $\mathrm{p}<0,05$ \\
\hline $\begin{array}{l}\text { 5. A lei que regulamenta o abortamento está contida no Código Civil } \\
\text { Brasileiro }\end{array}$ & $\begin{array}{c}10 \\
(55,55)\end{array}$ & $\begin{array}{c}8 \\
(44,45)\end{array}$ & $\begin{array}{c}28 \\
(66,67)\end{array}$ & $\begin{array}{c}14 \\
(33,33)\end{array}$ & $0,5<\mathrm{p}<0,1$ \\
\hline $\begin{array}{l}\text { 6. O abortamento constitui uma das principais causas de mortalidade } \\
\text { materna no país }\end{array}$ & $\begin{array}{c}11 \\
(61)\end{array}$ & $\begin{array}{c}7 \\
(39)\end{array}$ & $\begin{array}{c}31 \\
(73,8)\end{array}$ & $\begin{array}{c}11 \\
(26,2)\end{array}$ & $0,5<\mathrm{p}<0,1$ \\
\hline 7. A ocitocina é o fármaco de escolha para indução de abortamento & $\begin{array}{c}2 \\
(11)\end{array}$ & $\begin{array}{c}16 \\
(89)\end{array}$ & $\begin{array}{c}19 \\
(45,23)\end{array}$ & $\begin{array}{c}23 \\
(54,77)\end{array}$ & $\mathrm{p}<0,05$ \\
\hline
\end{tabular}

Grupo controle: Hospital Estadual Mário Covas; Grupo de estudo: Hospital da Mulher Maria José dos Santos Stein; V: afirmação verdadeira; F: afirmação falsa; * não houve significância.

As respostas referentes ao grau de conhecimento da legislação brasileira sobre o abortamento estão demonstradas na Tabela 3 . Mais de nove por cento $(9,6 \%)$ dos médicos do GC consideraram que a gestação resultante de estupro não tem amparo legal para ser interrompida no Brasil e $20 \%$ dos participantes deste mesmo grupo consideraram que é permitido em caso em que a mulher não tem condições mentais para a maternidade. Nenhum participante do GE concordou com estas assertivas. Quanto à permissão legal de interrupção da gestação decorrente de risco de morte da gestante, $22 \%$ e $14 \%$ do GE e GC, respectivamente, responderam que esta prática não é legal. Ambos os grupos $(55,55 \%$ do GE e $61,9 \%$ do GC) consideraram que não está amparada por lei a interrupção da gestação em caso de feto com má formação. No quesito referente à autonomia do médico em proceder com o abortamento diante do diagnóstico inequívoco de anencefalia, a pedido da gestante, independentemente de autorização do Estado, 72,22 \% dos respondentes do GE e 76,19\% do GC consideraram esta condição falsa. Quanto à conduta diagnóstica de anencefalia a maioria dos respondentes dos dois grupos relatou que o exame de ultrassonografia está indicado a partir da $12^{\mathrm{a}}$ semana de gestação, exceto para $16 \%$ deles em ambos os grupos. A maioria também considerou que o abortamento somente pode ser realizado após a obtenção do laudo do Instituto Médico Legal (IML), GE 72,22\% e GC 64,3\%, mas 16\% do GE e $23,3 \%$ do GC demonstraram desconhecimento quanto aos serviços médicos de referência para casos 
França Junior RR et al. Abortamento legal: comparação do grau de conhecimento de médicos de um hospital especializado.

de abortamento legal oferecidos pelo Sistema Único de Saúde (SUS). Quanto à documentação necessária para o procedimento de abortamento legal em caso de estupro $66,67 \%$ do GE e $73,8 \%$ GC não consideraram que a apresentação do termo de consentimento livre e esclarecido por escrito é documento suficiente. A maioria dos participantes considerou que não é necessária a autorização do marido da gestante $(94,44 \%$ GE e $80,95 \%$ do GC). No quesito sobre a guarda do segredo médico diante de um diagnóstico de abortamento clandestino, 27,78\% do GE e 47,6\% dos respondentes do GC consideraram a possibilidade de quebra do sigilo.

Tabela 3. Proporção de resposta dos grupos sobre a legislação brasileira referente ao abortamento e o grau de significância $\chi 2$ $(\mathrm{p}<0,05)$

\begin{tabular}{|c|c|c|c|c|c|}
\hline \multirow[t]{2}{*}{ Afirmativas } & \multicolumn{2}{|c|}{$\begin{array}{l}\text { Grupo de } \\
\text { estudo }(\%)\end{array}$} & \multicolumn{2}{|c|}{$\begin{array}{c}\text { Grupo controle } \\
(\%) \\
\end{array}$} & \multirow[t]{2}{*}{$\chi^{2}(\mathbf{p})$} \\
\hline & $\mathrm{V}$ & $\mathrm{F}$ & $\mathrm{V}$ & $\mathrm{F}$ & \\
\hline 1-É permitido o abortamento em gravidez resultante de estupro & 100 & 0 & 90,4 & 9,6 & $0,5<\mathrm{p}<0,10$ \\
\hline $\begin{array}{l}\text { 2-É permitido o abortamento quando a mulher não tem condições } \\
\text { mentais para ser mãe }\end{array}$ & 0 & 100 & 19,05 & 80,95 & $\mathrm{p}<0,05$ \\
\hline $\begin{array}{l}\text { 3-É permitido o abortamento quando houve falha do método } \\
\text { anticoncepcional }\end{array}$ & 0 & 100 & 0 & 100 & $*$ \\
\hline 4-É permitido o abortamento quando há risco de vida da gestante. & 77,78 & 22,22 & 85,71 & 14,29 & $0,5<\mathrm{p}<0,10$ \\
\hline $\begin{array}{l}\text { 5-É permitido o abortamento quando o feto apresenta má formação } \\
\text { congênita grave. }\end{array}$ & 44,45 & 55,55 & 38,1 & 61,90 & $0,90<\mathrm{p}<0,50$ \\
\hline $\begin{array}{l}\text { 6-Para que seja realizado abortamento legal é necessário laudo do } \\
\text { Instituto Médico Legal. }\end{array}$ & 27,78 & 72,22 & 35,7 & 64,30 & $0,9<\mathrm{p}<0,50$ \\
\hline $\begin{array}{l}\text { 7-Na ocorrência do diagnóstico inequívoco de anencefalia o médico } \\
\text { pode, a pedido da gestante, independente de autorização do Estado, } \\
\text { interromper a gravidez. }\end{array}$ & 27,78 & 72,22 & 23,81 & 76,19 & $0,90<\mathrm{p}<0,50$ \\
\hline $\begin{array}{l}\text { 8-O diagnóstico de anencefalia é feito por exame ultrassonográfico } \\
\text { realizado a partir da } 12^{\text {a }} \text { (décima segunda) semana de gestação. }\end{array}$ & 83,33 & 16,67 & 83,33 & 16,67 & $*$ \\
\hline 9-O SUS oferece serviços de referência para abortamento legal & 83,33 & 16,67 & 76,20 & 23,8 & $0,50<\mathrm{p}<010$ \\
\hline $\begin{array}{l}\text { 10-Quando a mulher opta pelo abortamento permitido na legislação, } \\
\text { o único documento a ser apresentado é o termo de consentimento } \\
\text { escrito, que deve ser anexado ao prontuário médico. }\end{array}$ & 33,33 & 66,67 & 26,20 & 73,8 & $0,90<\mathrm{p} 0,50$ \\
\hline $\begin{array}{l}\text { 11-Em suspeita de abortamento clandestino o médico não pode } \\
\text { denunciar a gestante, salvo em justa causa. }\end{array}$ & 72,22 & 27,78 & 52,40 & 47,6 & $0,5<\mathrm{p}<0,10$ \\
\hline $\begin{array}{l}\text { 12-Para realização de abortamento legal é necessária autorização do } \\
\text { marido da gestante. }\end{array}$ & 5,56 & 94,44 & 19,05 & 80,95 & $0,5<\mathrm{p}<0,10$ \\
\hline
\end{tabular}

Grupo controle: Hospital Estadual Mário Covas; Grupo de estudo: Hospital da Mulher Maria José dos Santos Stein:

V: afirmação verdadeira; F: afirmação falsa; * não houve significância; SUS: Sistema Único de Saúde.

\section{DISCUSSÃO}

No Brasil, o abortamento é crime tipificado pelo Código Penal brasileiro exceto em duas situações previstas no artigo 128 (incisos I e II) que concedem à mulher o direito de interrupção da gestação, são elas: gestação decorrente de estupro, também denominado de abortamento sentimental; ou quando há risco de morte materna, considerado como abortamento necessário. Mais recentemente, foi descriminalizada a antecipação terapêutica do parto de feto anencéfalo ${ }^{15}$. Apesar dessas prerrogativas legais, muitas mulheres não têm acesso ao abortamento seguro, seja por falta de conhecimento, por orientação inadequada recebida de profissionais da saúde ou por falta de acesso ao serviço médico. Estes três fatores, isolados ou em conjunto, podem contribuir 
para a demora de atendimento com consequente impossibilidade clínica de realização do abortamento em decorrência da avançada idade gestacional. Estudos realizados no Brasil mostram que significativa parcela de médicos desconhece as possibilidades de abortamento legal ou não tem informações suficientes para conduzirem o caso de forma precisa ${ }^{8}$ favorecendo o atraso no encaminhamento destas mulheres para serviços especializados que realizam o abortamento de forma segura.

Esse estudo foi elaborado para averiguar o grau de conhecimento que médicos de dois serviços públicos, comparando as respostas entre médicos que trabalham em hospital especializado no atendimento de mulheres com os que atuam em hospital geral. Independentemente da especificidade de atendimento é necessário que os profissionais de saúde saibam quais são as prerrogativas legais nos casos de abortamento e façam as orientações pertinentes.

Abortamento inseguro que é considerado uma pandemia evitável, segundo a Organização Mundial da Saúde $(\mathrm{OMS})^{16}$, é definido como um procedimento que interrompe a gravidez de forma intencional realizado por pessoa não habilitada e/ou em ambiente em desacordo com as normas médicas minimamente ideais ${ }^{16}$. Segundo Haddad et al. ${ }^{17}$, cerca de 42 milhões de mulheres anualmente recorrem ao abortamento por gestações indesejadas e 68.000 morrem em decorrência de procedimento inseguro, representando $13 \%$ das causas de mortalidade materna. No Brasil é estimado que entre 728.100 a 1.039 .000 mulheres recorram ao abortamento clandestino a cada ano, com a taxa atual de 3,7 abortamentos por 100 mulheres em idade reprodutiva. Esses dados, provavelmente, são inferiores à realidade, posto que, por ser ilegal, a prática é subnotificada e representa grave problema de saúde em decorrência das complicações clínicas (alta taxa de morbimortalidade) destes procedimentos, principalmente entre as mulheres de classes socioeconômicas menos providas ${ }^{15,18}$.

Nosso estudo mostrou que mais de um quarto dos participantes do GC e mais de um terço do GE consideraram que o abortamento não constitui uma das principais causas de mortalidade materna no país. Entre 1992 e 2005 foram computadas 1.054.242 hospitalizações na rede pública e registradas no Sistema de Informação Hospitalar (SIH) do SUS, devidas a abortamento, representando a taxa média de 2,07 abortamentos por 100 mulheres entre 15 a 49 anos de idade $^{19}$. Estudo conduzido por Singh $^{20}$ mostrou que a taxa de hospitalização decorrente de complicação de abortamento no Brasil em 1991 foi de 8,1/1000 mulheres. Neste mesmo estudo, os países que mostraram maior taxa foram Uganda (16,4/1000 em 2002), Egito $\left(15 / 1000\right.$ em 1996) e Chile (10/1000 em 1990) ${ }^{20}$. Quanto à mortalidade, dados publicados pelo SUS indicam que a incidência de óbitos por complicações de abortamento no Brasil oscila em torno de $12,5 \%$, ocupando o terceiro lugar entre as causas de mortalidade materna ${ }^{21}$. Em 2004, foi publicado estudo que analisou as declarações de óbitos do ano de 2002 confirmando que a terceira causa de mortalidade materna $(11,4 \%$ - $15 \%)$ foi abortamento $^{22}$. De acordo com a OMS, as principais causas de mortes em consequência ao abortamento não seguro são: hemorragia, sepses, trauma genital e necrose de intestino ${ }^{23}$. Segundo as respostas dos participantes da pesquisa, tanto os do GC quanto os do GE, as altas taxas de hospitalização e de mortalidade decorrentes de complicações de abortamentos clandestinos no Brasil representam importante problema de saúde pública, pois implicam em riscos às gestantes, entretanto esta prática não contribui para o controle de natalidade. Os respondentes do GC não consideraram que o abortamento seja solução para número excessivo da prole, contrário ao entendimento dos médicos do GE. De acordo com o Ministério da Saúde, a minoria das mulheres que recorrem ao abortamento $(9,5 \%$ a $29,2 \%)$ não tinha filhos, dado esse que leva a inferir que o abortamento pode ser considerado como instrumento de planejamento familiar importante para as mulheres com filhos quando os métodos contraceptivos falham ou não são utilizados ${ }^{17}$. Outro estudo mostra que o perfil de mulheres que recorrem ao abortamento é de jovens, com baixo nível de escolaridade e que não têm a prática do uso de métodos contraceptivos ou o fazem de forma irregular $^{24}$.

Os médicos do GC responderam que a ocitocina é o fármaco de escolha para indução de abortamento. Vale ressaltar que o fármaco de escolha para indução de abortamento é o misoprostol, análogo sintético da prostaglandina E1. Estudo brasileiro que analisou o conhecimento de alunos de Medicina sobre o uso de misoprostol para abortamento medicamentoso apontou que apenas $8 \%$ dos alunos do sexto ano de três escolas médicas apresentaram conhecimento satisfatório de seu uso e efeitos ${ }^{25}$.

As normas legais que regem a questão de abortamento variam entre os países. Dos respondentes desta pesquisa, mais da metade, 66,67\% GC e $55,55 \%$ GE, demostraram desconhecimento quanto à legislação brasileira que regula a questão de abortamento e afirmaram que o Código Civil Brasileiro é a lei regulamentadora. Entretanto, é o Código Penal Brasileiro, artigos 124-129, que estabelece as determinações legais sobre o abortamento ${ }^{2}$.

A maioria dos participantes desse estudo concordou que no Brasil é permitida a interrupção legal da gestação quando esta é decorrente de estupro (abortamento sentimental) e nos casos de risco de morte da gestante (abortamento terapêutico), mas significativa porcentagem não considerou a malformação fetal 
França Junior RR et al. Abortamento legal: comparação do grau de conhecimento de médicos de um hospital especializado.

incompatível com a vida extrauterina uma possível indicação de abortamento legal; uma presumível explicação para este alto índice de resposta incorreta pode ser justificado pela generalização da pergunta, pois não foi especificada a anencefalia, embora outras malformações inviáveis com a vida extrauterina também possam motivar a interrupção da gestação por ordem judicial. Para que o abortamento legal seja possível, $35,7 \%$ do GE e $27,78 \%$ do GC responderam que há necessidade de laudo emitido pelo Instituto Médico Legal (IML) para a viabilização do abortamento, mas de acordo com Hélio Gomes, atualizado por Hygino Hércules $^{26}$, 2004, em casos de abortamento terapêutico (risco de morte da gestante) o médico pode proceder com o ato mesmo contra a vontade da mulher, sendo dessa forma excludente de ilicitude por se tratar de caso de necessidade; entretanto, em caso de abortamento sentimental (resultante de estupro) o procedimento é diferente, existindo a necessidade de autorização da mulher por escrito, mas sem necessidade de realização de perícia pelo IML. A apresentação de documento oficial comprovando o alegado estupro, autorização judicial ou certidão médico-legal, é uma forma de o médico garantir que o que está sendo afirmado de fato ocorreu, evitando problemas legais futuros ${ }^{26}$. Contudo, a Portaria $n^{\circ}$. $1.508 / \mathrm{GM}$, de $1^{\mathrm{o}}$ de setembro de $2005^{14}$, do Ministério da Saúde, disciplina as medidas assecuratórias da licitude do procedimento de interrupção da gravidez nos casos previstos em lei quando realizado no âmbito do SUS, conferindo aos profissionais da saúde segurança jurídica, baseada na Norma Técnica sobre Prevenção e Tratamento dos Agravos Resultantes da Violência Sexual contra Mulheres e Adolescentes que não obriga as vítimas de estupro da apresentação do Boletim de Ocorrência. Dessa forma, conclui-se que o Código Penal não exige qualquer documento - boletim de ocorrência policial, laudo do IML ou autorização judicial - para a prática do abortamento no caso de estupro, a não ser o consentimento da mulher; mas a mulher deve ser orientada a procurar a polícia para que o crime seja investigado $^{27}$. A maioria dos médicos de ambos os hospitais entendeu que apenas o termo de consentimento expressado pela gestante ou representante legal não é suficiente para a interrupção legal da gestação $(66,66 \%$ do GE e 73,8\% do GC). Dos participantes, 72,22\% do GE e $76,19 \%$ do GC demostraram desconhecimento quanto às normativas do CFM no que tange aos casos de anencefalia. A Resolução CFM no. 1.989/2012 determina que o médico, diante do diagnóstico inequívoco de anencefalia (ausência da calota craniana e de parênquima cerebral identificável), pode, a pedido da mulher, realizar o procedimento independentemente da autorização do Estado ${ }^{5}$. O diagnóstico de anencefalia deve ser realizado por exame de ultrassonografia realizado a partir da $12^{\mathrm{a}}$ semana de gestação, documentado com duas fotografias, devidamente identificadas e datadas, mostrando a face do feto em posição sagital e do polo cefálico no corte transversal. O laudo do exame de ultrassonografia precisa ser assinado por dois médicos capacitados. A indicação de interrupção da gestação de feto anencéfalo extrapola a questão do direito da vida, posto que a mortalidade desse concepto seja certa, mas tange à questão dos direitos da gestante ${ }^{28}$. Embora somente a anencefalia seja considerada como a malformação fetal passível de abortamento permitido por lei, casos de gestação de gêmeos unidos sem prognóstico de sobrevida pós-natal também têm recebido sentenças favoráveis ${ }^{29}$.

Embora a maioria dos médicos tenha respondido que o SUS oferece atendimento especializado, 16,67\% do GE e $23,8 \%$ do GC mostraram desconhecimento. Atualmente o SUS oferece unidades de referência para realização legal da interrupção da gravidez, garantindo o direito da mulher.

A conduta ética do médico em manter o sigilo diante da suspeita ou confirmada prática de abortamento foi outra questão abordada; $52 \%$ dos médicos do GC e $72 \%$ do GE consideraram que, em suspeita de abortamento clandestino, o médico não pode denunciar a gestante, salvo em justa causa. Estes dados apontam que $48 \%$ dos médicos do GC não têm conhecimento do Código de Ética Médica. Art. $73^{30}$ - "Revelar o fato de que tenha conhecimento em virtude do exercício de sua profissão, salvo por justa causa, dever legal ou autorização expressa do paciente".

Diante do exposto, o desconhecimento dos profissionais de saúde sobre as indicações legais de abortamento pode representar o atraso significativo no atendimento de gestantes implicando em contraindicação do procedimento devido à idade gestacional avançada, causando danos à gestante a aos familiares. Tais atitudes, além de irem contra as normas legais, ferem a ética médica.

\section{CONCLUSÕES}

No presente estudo, os dois grupos mostraram desconhecimento sobre grande parte das questões envolvidas em abortamento legal, sem diferença significativa entre eles. Apenas em três situações o grupo de médicos do hospital especializado mostrou maior conhecimento e elas se referiram a: doença mental da gestante, controle de natalidade e utilização da ocitocina como fármaco indutor de abortamento. Este estudo foi um projeto piloto e os resultados somente podem ser aplicados aos grupos estudados. 
França Junior RR, Braga MV, Miziara CSMG, Miziara ID Legal abortion: comparison of the extent of the knowledge of doctors at a women's care hospital and a general hospital. Saúde, Ética \& Justiça. 2015;20(2):57-65.

ABSTRACT: In Brazil, abortion is considered a crime except under some conditions. Therefore, it is essential that health professionals be well informed about such situations so that they can act properly in dealing with cases under such conditions. The aim of this study was to compare the level of knowledge regarding abortion law in Brazil of doctors in a women's care hospital with doctors at a general hospital in the city of Santo André. To achieve this purpose a structured questionnaire, approved by the Medical Ethics Committee, was applied regarding issues related to abortion. The result of this study showed no significant difference between the two groups in terms of the social and legal issues involved in abortion, except in three situations in which the group of women's care hospital doctors showed increased knowledge on issues involving mentally ill pregnant women, birth control and the use of oxytocin as a drug for inducing abortion.

KEY WORDS: Abortion; Abortion, legal; Abortion, therapeutic; Legislation; Hospitalists/legislation \& jurisprudence.

\section{REFERÊNCIAS}

1. Brasil. Ministério da Saúde. Aspectos jurídicos do atendimento às vítimas de violência sexual: perguntas e respostas para profissionais de saúde. $2^{\mathrm{a}}$ ed. Brasília, DF: Editora MS; 2011 [Acesso em 04 dz 2014]. Disponível em: http://bvsms.saude.gov.br/bvs/publicacoes/aspectos juridicos_atendimento_vitimas_violencia_2ed.pdf.

2. Brasil. Presidência da República, Casa Civil, Subchefia para Assuntos Jurídicos. Decreto-Lei $\mathrm{n}^{\circ}$ 2.848, de 7 de dezembro de 1940. Código penal. Rio de Janeiro; 1940. [Acesso em 15 jan 2015]. Disponível em: http://www. planalto.gov.br/ccivil_03/decreto-lei/Del2848.htm

3. França GV. Aborto legal e aborto criminoso. In: Franca GV. Medicina Legal. 9 ${ }^{a}$ ed. Rio de Janeiro: Guanabara Koogan; 2011. p.306.

4. Brasil. Supremo Tribunal Federal. Arguição de descumprimento de preceito fundamental 54-8 Distrito Federal. Brasília; 2008. [Acesso em 10 mai 2015]. Disponível em: http://www.stf.jus.br/arquivo/ cms/processoAudienciaPublicaAdpf54/anexo/ adpf54audiencia.pdf

5. Conselho Federal de Medicina (CFM). Resolução $\mathrm{n}^{0}$ $1.989 / 2012$. Dispõe sobre o diagnóstico de anencefalia para a antecipação terapêutica do parto e dá outras providências. Brasília; 2012 [Acesso em 10 mai 2015]. Disponível em: http://www.portalmedico.org.br/ resolucoes/CFM/2012/1989_2012.pdf.

6. Brasil. Ministério da Saúde. Atenção humanizada ao abortamento: Norma técnica. 2a ed. Brasília: Editora MS; 2011 [Acesso em 10 mai 2015]. Disponível em: http://bvsms.saude.gov.br/bvs/publicacoes/atencao_ humanizada_abortamento_norma_tecnica_2ed.pdf

7. Brasil. Presidência da República, Casa Civil, Subchefia para Assuntos Jurídicos. Lei ${ }^{\circ} 10.406$, de 10 de janeiro de 2002. Institui o Código Civil. Brasília; 2002 [Acesso em 10 mai 2015]. Disponível em: http://www.planalto. gov.br/CCivil_03/leis/2002/L10406.htm

8. Loureiro DC, Vieira EM. Aborto: conhecimento e opinião de médicos dos serviços de emergência de Ribeirão Preto,
São Paulo, Brasil, sobre aspectos éticos e legais. Cad Saúde Pública. 2004;20(3):679-88. DOI: http://dx.doi. org/10.1590/S0102-311X2004000300004

9. Faundes A, Duarte GA, Andalaft Neto J, Olivatto AE, Simoneti RM. Conhecimento, opinião e conduta de ginecologistas e obstetras brasileiros sobre o aborto induzido. Rev Bras Ginecol Obstet. 2004;26(2): 89-96. DOI: http://dx.doi.org/10.1590/S010072032004000200002 .

10. Darzé OISP, Azevêdo BKG. Competências adquiridas durante a formação médica e as opiniões e atitudes sobre o aborto. Rev Bras Ginecol Obstet. 2014;36(1):5-9. DOI: http://dx.doi.org/10.1590/S0100-72032014000100003.

11. Brasil. Ministério da Saúde. Prevenção e tratamento dos agravos resultantes da violência sexual contra mulheres e adolescentes: norma técnica. $2^{\mathrm{a} e d . ~ B r a s i ́ l i a, ~ D F: ~ E d i t o r a ~}$ MS; 2005 [Acesso em 17 jun 2015]. Disponível em: http://bvsms.saude.gov.br/bvs/publicacoes/caderno6_ saude_mulher.pdf

12. Brasil. Presidência da República, Casa Civil, Subchefia para Assuntos Jurídicos. Lei n ${ }^{\circ} 11.340$, de 7 de agosto de 2006. Cria mecanismos para coibir a violência doméstica e familiar contra a mulher, nos termos do $\S 8^{\circ}$ do art. 226 da Constituição Federal, da Convenção sobre a Eliminação de Todas as Formas de Discriminação contra as Mulheres e da Convenção Interamericana para Prevenir, Punir e Erradicar a Violência contra a Mulher; dispõe sobre a criação dos Juizados de Violência Doméstica e Familiar contra a Mulher; altera o Código de Processo Penal, o Código Penal e a Lei de Execução Penal; e dá outras providências. Brasília, DF; 2006 [Acesso em 17 jun 2015]. Disponível em: http://www.planalto.gov.br/ ccivil_03/_ato2004-2006/2006/lei/111340.htm

13. Brasil. Presidência da República, Casa Civil, Subchefia para assuntos jurídicos. Lei ${ }^{\circ} 10.778$, de 24 de novembro de 2003. Estabelece a notificação compulsória, no território nacional, do caso de violência contra a mulher que for atendida em serviços de saúde públicos ou privados. Brasília, DF; 2003 [Acesso em 11 mai 2015]. 
França Junior RR et al. Abortamento legal: comparação do grau de conhecimento de médicos de um hospital especializado.

Disponível em: http://www.planalto.gov.br/ccivil 03/ leis/2003/L10.778.htm

14. Brasil. Ministério da Saúde. Portaria $n^{\circ} 1.508 / \mathrm{GM}$, de $1^{\circ}$ de setembro de 2005. Dispõe sobre o Procedimento de Justificação e Autorização da Interrupção da Gravidez nos casos previstos em lei, no âmbito do Sistema Único de Saúde - SUS. Brasília, DF; 2005. [Acesso em 11 mai 2015]. Disponível em: http://pfdc.pgr.mpf.mp.br/ atuacao-e-conteudos-de-apoio/legislacao/mulher/ Portaria\%201508\%20aborto.pdf

15. Brasil. Ministério da Saúde. Magnitude do aborto no Brasil: aspectos epidemiológicos e sócio-culturais. Abortamento previsto em lei em situações de violência sexual: perspectivas e experiências das mulheres. Brasília, DF: Editora MS; 2008 [Acesso em 17 mai 2015]. Disponível em: http://bvsms.saude.gov.br/bvs/ publicacoes/magnitude_aborto_brasil.pdf

16. The prevention and management of unsafe abortion: Report of a Technical Working Group, 1992; Genebra. Meeting of the technical working group on unsafe abortion. Genebra: Division of Family Health; 1993. [Cited 2015 Jun 6]. Disponível em: http://whqlibdoc. who.int/hq/1992/WHO MSM 92.5.pdf.

17. Haddad LB, Nour NM. Unsafe abortion: unnecessary maternal mortality. Rev Obstet Gynecol. 2009;2(2):122-6.

18. Brasil. Ministério da Saúde. 20 anos de pesquisa sobre aborto no Brasil. Brasília, DF: Editora MS; 2009. [Acesso em 10 jun 2015]. Disponível em: http://bvsms.saude.gov. br/bvs/publicacoes/livreto.pdf

19. Monteiro MFG, Adesse L. Estimativas de aborto induzido no Brasil e grandes regiões (1992-2005). In: XV Encontro Nacional de Estudos Populacionais, ABEP; 2006 set 18-22; Caxambu, MG. Belo Horizonte: ABEP; 2006. p. 1-10. [Acesso em 20 dez 2014]. Disponível em: http://www.abep.nepo.unicamp.br/encontro2006/ docspdf/abep2006_252.pdf.

20. Singh S. Hospital admissions resulting from unsafe abortion: estimates from 13 developing countries. Lancet. 2006;368(9550):1887-92. DOI: http://dx.doi. org/10.1016/S0140-6736(06)69778-X.

21. Mariutti MG, Furegato ARF, Scatena MCM, Silva L. Relação de ajuda entre o enfermeiro e mulheres em abortamento espontâneo. Cienc Cuid Saude. 2005;4(1):83-8. DOI: http://dx.doi.org/10.4025/ cienccuidsaude.v4i1.5376

22. Laurenti R, Mello Jorge MHP, Gotlieb SLD. A mortalidade materna nas capitais brasileiras: algumas características e estimativas de um fator de ajuste. Rev Bras Epidemiol. 2004;7(4):449-60. DOI: http://dx.doi. org/10.1590/S1415-790X2004000400008.

23. World Health Organization (WHO). Unsafe abortion: global and regional estimates of the incidence of unsafe abortion and associated mortality in 2003. 5th ed. Geneva: WHO; 2007. [Acesso em 15 jul 2015]. Available from: http://apps.who.int/iris/ bitstream/10665/43798/1/9789241596121_eng.pdf

24. Rocha MIB, Barbosa RM, organizadoras. Aborto no Brasil e países do Cone Sul: Panorama da situação e dos estudos acadêmicos. Campinas: Núcleo de Estudos de População - Nepo/Unicamp; 2009 [Acesso em 2 jul 2015]. Disponível em: http://www.nepo.unicamp.br/ textos/publicacoes/livros/aborto/aborto.pdf.

25. Fernandes KG. O conhecimento de estudantes de medicina do Estado de São Paulo sobre aborto medicamentoso. Rev Bras Ginecol Obstet. 2013;35(7):336. DOI: http:// dx.doi.org/10.1590/S0100-72032013000700010.

26. Gomes H. Medicina legal. $33^{\mathrm{a}}$ ed. Rio de Janeiro: Freitas Bastos Editora; 2004.

27. Brasil. Ministério da Saúde. Cadernos de atenção básica. Saúde sexual e saúde reprodutiva. Brasília, DF: Editora MS; 2010. [Acesso em 30 jun 2015]. Disponível em: http://189.28.128.100/dab/docs/publicacoes/cadernos ab/abcad26.pdf.

28. Marta GN, Marta TN. Aborto de fetos anencefálicos. Rev Assoc Med Bras. 2010;56(5):493-516. DOI: http:// dx.doi.org/10.1590/S0104-42302010000500005.

29. Nomura RMY, Brizot ML, Liao AW, Hernandez WR, Zugaib M. Gêmeos unidos e autorização judicial para o aborto. Rev Assoc Med Bras. 2011;57(2):205-10. DOI: http://dx.doi.org/10.1590/S0104-42302011000200020.

30. Conselho Federal de Medicina (CFM). Resolução ${ }^{\circ}$ 1931/2009. Aprova o Código de Ética Médica. Brasília, DF; 2009 [Acesso em 15 jul 2015]. Disponível em: http:// www.portalmedico.org.br/novocodigo/integra.asp. 